\title{
Clinical Characteristics of Withdrawal of Basal Insulin Therapy Among Japanese Patients with Type 2 Diabetes: A Multicenter Retrospective Observational Study
}

\author{
Shuhei Nakanishi (D) Masashi Shimoda - Fuminori Tatsumi - Kenji Kohara Atsushi Obata \\ Junpei Sanada · Yoshiro Fushimi · Takatoshi Anno · Fumiko Kawasaki • Tomoatsu Mune • \\ Kohei Kaku • Hideaki Kaneto
}

Received: January 16, 2021 / Accepted: May 8, 2021 / Published online: May 28, 2021

(C) The Author(s) 2021

\section{ABSTRACT}

Introduction: This study aimed to examine retrospectively the clinical backgrounds of Japanese patients with type 2 diabetes (T2D) who successfully withdrew from insulin use after being started on basal insulin in an outpatient setting.

Methods: The study population comprised 376 insulin-naïve patients who were started on basal insulin (glargine U100, glargine U300, or degludec) for the management of T2D and followed the treatment regimen for at least 6 months in 13 institutions in Japan. The clinical courses of the study participants were compared based on outpatient clinic medical records for the three different types of basal insulin prescribed by categorizing the participants into two groups retrospectively: those who successfully withdrew from insulin therapy and those who did not, during a 6-month observation period. The clinical determinants

S. Nakanishi $(\bowtie) \cdot$ M. Shimoda · F. Tatsumi .

K. Kohara · A. Obata · J. Sanada · Y. Fushimi .

T. Mune $\cdot$ H. Kaneto

Division of Diabetes, Metabolism and

Endocrinology, Kawasaki Medical School, Okayama,

Japan

e-mail: n-shuhei@umin.net

T. Anno · F. Kawasaki · K. Kaku

Department of Internal Medicine, Kawasaki Medical

School, Okayama, Japan for insulin withdrawal were assessed using a Cox proportional hazard model.

Results: Glycated hemoglobin was improved in all participants regardless of basal insulin type. Of the 376 study participants, 61 successfully withdrew from basal insulin therapy. After adjustment was made for several confounders, the positive determinant factors for successful withdrawal of insulin were short duration of diabetes and high body mass index at the start of study, and the negative determinant factor was use of insulin secretagogues at the start. The types of basal insulin used by the study participants were not significant determinants of successful insulin withdrawal in this study.

Conclusions: Use of basal insulin is a powerful option for the treatment of T2D. In patients with high BMI and/or short duration of diabetes, short-term insulin therapy is a promising strategy for the treatment of T2D before the initiation of insulin secretagogues, since such patients have the potential to successfully withdraw from basal insulin use even in an outpatient setting.

Keywords: Insulin therapy withdrawal; Glucotoxicity; Type 2 diabetes 


\section{Key Summary Points}

Why carry out this study?

There are only a few reports of data related to the successful withdrawal of basal insulin use in the real world. This study aimed to examine retrospectively the clinical backgrounds of Japanese patients with type 2 diabetes (T2D) who successfully withdrew from insulin use after being started on basal insulin in an outpatient setting.

\section{What was learned from the study?}

The positive determinant factors for successful withdrawal of insulin use were short-term duration of diabetes and high body mass index (BMI) at the start of study, and the negative determinant factor was use of insulin secretagogues at the start.

The types of basal insulin used by the study participants were not significant determinants of successful withdrawal of insulin in this study.

In patients with high BMI and/or short duration of diabetes, short-term basal insulin use is a promising strategy for the treatment of T2D before the initiation of insulin secretagogues even in an outpatient setting.

\section{DIGITAL FEATURES}

This article is published with digital features, including a summary slide, to facilitate understanding of the article. To view digital features for this article go to https://doi.org/10.6084/ m9.figshare.14555409.

\section{INTRODUCTION}

Type 2 diabetes mellitus (T2D) is a chronic metabolic disease affecting populations worldwide that has become an important public health challenge in not only Japan but also other Asian countries [1, 2]. The goal for patients with diabetes is to secure years of healthy life by controlling this metabolic disorder and thereby maintain a quality of life that is equivalent to that of their healthy counterparts. To achieve this objective, it is important to prevent the onset and progression of various diabetic complications through strict glycemic control. However, evidence from the UK Prospective Diabetes Study (UKPDS) shows that beta-cell function deteriorates progressively over time in patients with T2D [3, 4]. Accordingly, basal insulin therapy, by improving betacell function and stabilizing the disease, is still of considerable value in the treatment of T2D. More recently, however, several oral antihyperglycemic agents (OAA) and injections of glucagon-like peptide 1 receptor agonists (GLP-1RA) have become available, and their use is recommended prior to initiation of basal insulin therapy [5].

Insulin therapy is an established option to improve glycemic control in patients with T2D, but in reality the method tends to be reserved for those with advanced-stage diabetes. Insulin glargine $100 \mathrm{U} / \mathrm{mL}$ (Gla100), insulin glargine $300 \mathrm{U} / \mathrm{mL}$ (Gla300), and insulin degludec 100 $\mathrm{U} / \mathrm{mL}$ (Deg) are long-acting, once-daily basal insulin analogues that are widely used in Japan. Although it is common to start basal insulin treatment once daily as a first step in insulin therapy for patients with T2D in an outpatient setting at clinics or hospitals, continuation of insulin therapy can represent a physical, clinical, and economic burden for patients. In addition, several studies have compared basal insulin analogues in terms of their effectiveness and safety [6-10], but no comparative study on the withdrawal of insulin use in outpatient settings has been available until now, at least among Japanese patients with T2D. There are a few reports showing data related to the successful withdrawal of insulin use, such as rate, 
clinical course in the real world, difference in choice of basal insulin, and their possible characteristics in comparison with participants who did not succeed at withdrawing from insulin use.

The primary objective of this multicenter retrospective observational study involving insulin-naïve Japanese outpatients with T2D was to assess the potential clinical characteristics of patients who successfully withdrew from insulin therapy by comparing them with those who did not, including the effect of the three different basal insulins-Gla100, Gla300, and Deg-in clinical use. The secondary objective was to investigate the differences in clinical usefulness of the three basal insulins by investigating the clinical courses of withdrawal as well as the continued use of the three insulin types.

\section{METHODS}

\section{Study Population and Patient Preparation}

The study design was retrospective in nature, and all data were obtained retrospectively from outpatient clinic medical records. The study was conducted in accordance with the declaration of Helsinki 1964 and its later amendments. Information pertaining to the study was provided to the public on a website (https://h. kawasaki-m.ac.jp/data/dept_010/ekigaku_s_dtl/ ) to give the participants the opportunity to optout, rather than informed consent being obtained from each individual patient, which in Japan is not a legal requirement at this point in time (under Japanese legislation). In addition, the study and its protocols were approved by the Kawasaki Medical School Hospital's ethics committee (No. 3215-1), the scientific research ethics committee at Murakami Memorial Hospital (201,901,160), Tsuchiya General Hospital's ethics committee (E181119-4), Kagawa Rosai Hospital's ethics committee (R15), Kurashiki Medical Center's ethics committee (910 [481]), and Hiroshima Kyoritsu Hospital's ethics committee (2018-12-21).

The study population comprised 241 men and 135 women who had regularly visited any of 13 outpatient institutions (5 clinics and 8 hospitals) in Japan for the treatment of T2D and who began to use daily injections of basal insulin-Gla100, Gla300, or Deg-as outpatients at some point between January 2015 and March 2018 due to poor glycemic control, based on the Treatment Guide for Diabetes 2010 (edited by the Japan Diabetes Society [11]). All participants at the start of the study were insulin-therapy naïve and were followed for a continuous period of at least 6 months regularly without hospitalization. Excluded from the study in advance were participants currently using steroids and/or GLP-1RA; those with active retinopathy, end-stage renal disease, ongoing treatment for malignancies or autoimmune disease; those starting use of rapid-acting insulin(s) concomitantly with basal insulin; and those younger than 20 years of age at the beginning of the follow-up period, hospitalized during the observation period, or deemed to be inappropriate for the study by the attending physician. Body mass index (BMI) was calculated as bodyweight (kg) divided by the square of standing height $(\mathrm{m})$. To investigate the association between the type of basal insulin and glycated hemoglobin (HbA1c), BMI, and insulin dose, in addition to withdrawal of insulin therapy, a dataset including information on OAA medication was compiled at the start (day 0 ) of the initiation of basal insulin and at 1 , 3 , and 6 months post initiation, respectively. Diabetes treatment, including medication and insulin dose during the follow-up period following initiation of basal insulin treatment and withdrawal of insulin treatment, was determined by the attending physician based on a patient-centered approach considering the best available evidence in terms of benefit, harm, patient values, preferences, and context in time-and not only target HbA1c level. Namely, the dose titration of basal insulin accompanying the choice of OAA was decided upon carefully by the attending physician to prevent hypoglycemia based on reference to data derived from laboratory-measured or self-monitored plasma glucose levels. Outpatient review was carried out every 2 to 8 weeks to ensure the strict maintenance of glycemic control. Successful withdrawal of insulin therapy was 
defined as the replacement of the basal insulin with diet management or OAA after decreases in insulin dose during the follow-up period at the outpatient clinic based on decisions made by the attending physician, taking into account glycemic control.

\section{Statistical Analysis}

The data from the study are expressed as the mean and standard deviation. Continuous variables at the start of the study were assessed using age- and gender-adjusted analysis of covariance to compare categories of clinical characteristics at baseline. Categorical variables were analyzed based on Fisher's exact test or chi-squared test. The measurements taken at the three visits $(1,3$, and 6 months) after the initiation of basal insulin therapy were analyzed using Wilcoxon signed-rank test based on comparison with the data obtained at the initiation of basal insulin use. Since BMI and HbA1c data were not normally distributed, these data were analyzed after logarithmic transformation. To compare the clinical courses of the patients on the three types of basal insulin or between participants withdrawing from insulin and participants continuing insulin therapy for 6 months, the trends over time of HbA1c, BMI, and medication used during the observation period were compared. In addition, to investigate the determinant factors for successful withdrawal of insulin use, the success of withdrawal or the continuation of insulin therapy during the 6-month period was designated as the dependent variable (1, withdrawal; 0 , continuation). Adjusted hazard ratios (HRs) for several determinants related to the withdrawal of insulin, such as age, gender, HbA1c, BMI, duration of diabetes, and specific medication(s), as well as choice of basal insulin (compared with Gla100), were estimated using a Cox proportional hazards model. Statistical analyses were performed using JMP software (version 13.2 for Windows; SAS Institute, Cary, NC, USA).

\section{RESULTS}

\section{Clinical Characteristics of Study Participants in the Deg, Gla100, and Gla300 Groups}

The clinical characteristics of all participants are given in Table 1 . At the start of the study, mean age, duration of T2D, HbA1c, and BMI were $63.1 \pm 12.9$ years, $\quad 10.3 \pm 8.4$ years, $\quad 10.1 \pm$ $2.0 \% \quad(86.8 \pm 21.7 \mathrm{mmol} / \mathrm{mol}), \quad$ and $25.2 \pm$ $4.6 \mathrm{~kg} / \mathrm{m}^{2}$, respectively.

During the observation period, 173, 101, and 102 participants were started on the basal insulin Deg, Gla100, or Gla300, respectively; of these participants, 32,13 , and 16 , respectively, successfully withdrew from insulin therapy. The rate of withdrawal from insulin therapy during the 6-month period did not differ among the three different insulin types $(P=0.46)$. Only the duration of diabetes differed among these insulin categories, with no changes observed in HbA1c or BMI at the beginning of the study or after 6 months. The clinical course of HbA1c showed significant decreases in all three categories. The BMI among participants who were started on Deg and Gla100 significantly increased during treatment, whereas the BMI among participants started on Gla300 did not.

Table 1 also shows the change in medication(s) at the beginning of the study and after 6 months in participants prescribed insulin secretagogues, such as sulfonylureas (SU) or glinides, biguanides (BG), alfa-glucosidase inhibitors $(\alpha-\mathrm{GI})$, dipeptidyl peptidase- 4 inhibitors (DPP-4I), thiazolidinediones (TZD), sodiumglucose co-transporter 2 inhibitors (SGLT2I), and GLP-1RA, or rapid-acting insulin. Use of the insulin secretagogues SGLT2I and TZD at the beginning of the study $(P<0.0001,<0.0001$, and 0.048) and after 6 months $(P<0.0001,<0.0001$, and 0.017$)$ resulted in significant differences among the three insulin categories. 
Table 1 Changes in clinical characteristics for each study group based on basal insulin type among patients with type 2 diabetes

\begin{tabular}{|c|c|c|c|}
\hline \multirow[t]{2}{*}{ Patient characteristics } & \multicolumn{3}{|c|}{ Initiation of basal insulin } \\
\hline & $\overline{\text { Deg }}$ & Gla100 & Gla300 \\
\hline $\mathrm{Ma} / \mathrm{e} /$ female $(n)$ & $108 / 65$ & $64 / 37$ & $69 / 33$ \\
\hline $\begin{array}{l}\text { Insulin withdrawal within } \\
6 \text { months, } n \text { (male/female) }\end{array}$ & $19 / 13$ & $9 / 4$ & $9 / 7$ \\
\hline Age (years) & $63.3 \pm 12.7$ & $63.7 \pm 11.8$ & $62.2 \pm 14.3$ \\
\hline Duration of diabetes (years) & $8.7 \pm 7.0^{* * * *}$ & $11.8 \pm 8.4$ & $11.6 \pm 9.9$ \\
\hline $\mathrm{SBP}(\mathrm{mmHg})$ & $130 \pm 18$ & $132 \pm 18$ & $135 \pm 21$ \\
\hline $\mathrm{DBP}(\mathrm{mmHg})$ & $77 \pm 10$ & $76 \pm 12$ & $76 \pm 14$ \\
\hline \multicolumn{4}{|l|}{ Dose of basal insulin (U/day) } \\
\hline First insulin dose & $5.9 \pm 1.9(173)^{* *}$ & $5.4 \pm 1.5(101)$ & $5.2 \pm 2.1(102)$ \\
\hline At 1 month & $7.2 \pm 3.0(169)^{* *,+}$ & $7.2 \pm 2.8(100)^{*}$ & $9.7 \pm 5.2(101)^{*, \pm}$ \\
\hline At 3 months & $8.5 \pm 4.6(159)^{* * * 亠}$ & $8.4 \pm 3.8(95)^{*}$ & $11.8 \pm 7.5(95)^{* . \$}$ \\
\hline At 6 months & $10.4 \pm 6.0(141)^{\ddagger}$ & $10.0 \pm 5.8(88)^{*}$ & $12.5 \pm 8.0(86)^{ \pm}$ \\
\hline \multicolumn{4}{|l|}{ HbAlc (\%) } \\
\hline At start of study & $10.03 \pm 1.93$ & $10.01 \pm 2.21$ & $10.29 \pm 1.85$ \\
\hline At 1 month & $9.05 \pm 1.44^{* * *+\vdots}$ & $8.95 \pm 1.52^{\ddagger}$ & $9.61 \pm 1.60^{* *+}$ \\
\hline At 3 months & $7.90 \pm 1.29^{* *, \ddagger}$ & $7.91 \pm 1.39^{\ddagger}$ & $8.47 \pm 1.44^{*}$ \\
\hline At 6 months & $7.65 \pm 1.31^{*}$ & $7.75 \pm 1.31^{\ddagger}$ & $7.92 \pm 1.51^{*}$ \\
\hline \multicolumn{4}{|l|}{$\mathrm{HbAlc}(\mathrm{mmol} / \mathrm{mol})$} \\
\hline At start of study & $86.08 \pm 21.04$ & $85.96 \pm 24.18$ & $88.97 \pm 20.27$ \\
\hline At 1 month & $75.44 \pm 15.72^{* *,+}$ & $74.37 \pm 16.65^{t}$ & $81.56 \pm 17.46^{*, *}$ \\
\hline At 3 months & $62.80 \pm 14.08^{* *,+}$ & $62.99 \pm 15.25$ & $69.12 \pm 15.76^{*, *}$ \\
\hline At 6 monthn & $60.10 \pm 14.36^{\ddagger}$ & $61.18 \pm 14.28$ & $63.02 \pm 16.45^{t}$ \\
\hline \multicolumn{4}{|l|}{ BMI $\left(\mathrm{kg} / \mathrm{m}^{2}\right)$} \\
\hline At start of study & $25.3 \pm 4.4$ & $25.2 \pm 4.7$ & $25.3 \pm 4.8$ \\
\hline At 1 month & $25.4 \pm 4.4$ & $25.3 \pm 4.6$ & $25.1 \pm 4.6$ \\
\hline At 3 months & $25.2 \pm 4.5$ & $25.4 \pm 4.5^{*}$ & $25.2 \pm 4.4$ \\
\hline At 6 months & $25.4 \pm 4.5 \dagger$ & $25.8 \pm 4.7^{\ddagger}$ & $25.2 \pm 4.4$ \\
\hline \multicolumn{4}{|c|}{ Treatment of diabetes with glimepiride, gliclazide, and glibenclamide, $n$ (dosage in $\mathrm{mg}$ )) } \\
\hline At start of study & $\begin{array}{l}25(1.04 \pm 0.71) / 5 \\
\quad(28.0 \pm 11.0) / 1(2.5)\end{array}$ & $\begin{array}{l}42(1.47 \pm 0.88) / 8 \\
\quad(35.0 \pm 20.0) / 1(2.5)\end{array}$ & $\begin{array}{c}22(1.38 \pm 0.82) / 4 \\
(20.0 \pm 0.0) / 6 \\
(1.67 \pm 0.65)\end{array}$ \\
\hline
\end{tabular}


Table 1 continued

\begin{tabular}{|c|c|c|c|}
\hline \multirow[t]{2}{*}{ Patient characteristics } & \multicolumn{3}{|c|}{ Initiation of basal insulin } \\
\hline & $\overline{\operatorname{Deg}}$ & Gla100 & Gla300 \\
\hline At 6 months & $\begin{array}{c}21(0.79 \pm 0.48) / 7 \\
(21.4 \pm 13.5) / 0\end{array}$ & $\begin{array}{c}33(1.12 \pm 0.87) / 9 \\
(21.1 \pm 14.5) / 0\end{array}$ & $\begin{array}{c}22(0.77 \pm 0.49) / 5 \\
(16.0 \pm 5.5) / 4 \\
(0.96 \pm 0.33)\end{array}$ \\
\hline \multicolumn{4}{|c|}{ Treatment of diabetes with rapid-acting insulin/SGLT2I/GLP-1RA/TZD $(n)$} \\
\hline At start of study & $0 / 53 / 0 / 8$ & $0 / 7 / 0 / 10$ & $0 / 23 / 0 / 13$ \\
\hline At 6 months & $11 / 67 / 7 / 6$ & $10 / 12 / 2 / 11$ & $3 / 34 / 2 / 12$ \\
\hline \multicolumn{4}{|c|}{ Treatment of diabetes with glinide/BG/ $\alpha$-GI/DPP-4I $(n)$} \\
\hline At start of study & $33 / 52 / 46 / 144$ & $6 / 33 / 21 / 89$ & $12 / 35 / 22 / 84$ \\
\hline At 6 months & $41 / 70 / 53 / 149$ & $10 / 40 / 24 / 88$ & $16 / 40 / 24 / 82$ \\
\hline
\end{tabular}

Data are shown as mean \pm standard deviation (SD) unless indicated otherwise

Deg Insulin degludec $100 \mathrm{U} / \mathrm{mL}$, Gla100 insulin glargine $100 \mathrm{U} / \mathrm{mL}$, Gla300 insulin glargine $300 \mathrm{U} / \mathrm{mL}, S B P$ systolic blood pressure, DBP diastolic blood pressure, HbAlc glycated hemoglobin, BMI body mass index, SGLT2I sodium-glucose cotransporter 2 inhibitors, GLP-1RA glucagon-like peptide 1 receptor agonist, $T Z D$ thiazolidinedione, $B G$ biguanide, $\alpha$ - $G I$ alpha-glucosidase inhibitors, $D P P-4 I$ dipeptidyl peptidase- 4 inhibitors

${ }^{*}$ Significant at $P<0.05$ compared with insulin glargine $\mathrm{U} 100 / \mathrm{mL}$ (Gla100) after adjustment for age and gender. ${ }^{* *}$ Significant at $P<0.05$ compared with Gla300 after adjustment for age and gender. ${ }^{\dagger}$ Signficant at $P<0.05$ compared with data at start of study. ${ }^{\dagger}$ Significant at $P<0.01$ compared with data at start of study

\section{Clinical Courses After Initiation of Basal Insulin in Participants Successfuly Withdrawing or Not from Insulin Use}

As presented in Table 2, the 61 participants who were able to successfully withdraw from basal insulin therapy (referred to as the $\mathrm{W}$ participants) had significantly higher HbA1c and BMI than the 315 participants who had to continue basal insulin therapy (C participants). However, at 3 and 6 months post initiation, those who successfully withdrew from insulin therapy (W) did have significantly lower HbA1c than those who could not $(\mathrm{C})$. In addition, the BMI did not differ at 3 and 6 months between the two categories of participants because the BMI of the $\mathrm{W}$ participants did not change significantly during the observation period, in contrast to the continuous and significant increase in the BMI of the C participants.

Regarding changes in medication(s), Table 2 presents data on the $\mathrm{W}$ and $\mathrm{C}$ participants taking the insulin secretagogues, BG, $\alpha-\mathrm{GI}, \mathrm{DPP}-4 \mathrm{I}$,
TZD, SGLT2I, and GLP-1RA or rapid-acting insulin at the beginning of the study, at 3 months, and at 6 months. Use of the insulin secretagogues, $\alpha$-GI and DPP-4I at the beginning of the study $(P<0.0001,0.014$, and 0.002) and the insulin secretagogues, BG, $\alpha$-GI, and DPP-4I, or rapid-acting insulin at 6 months $(P<0.0001$, $0.005,0.020,0.006$, and 0.026 ) resulted in significant differences between the two patient categories.

\section{HRs for Duration of Diabetes, BMI, HbA1c, and OAA in Relation to Withdrawal of Basal Insulin Use}

To calculate the HRs, a Cox regression model was used with withdrawal of basal insulin use as a dependent variable. Independent variables were age, gender, duration of diabetes, HbA1c, BMI, use of the insulin secretagogues BG, TZD, $\alpha$-GI, DPP-4I, and SGLT2I at the beginning of the study, in addition to use of GLP-1RA during the observation period, addition of rapid-acting 
Table 2 Comparison of clinical courses after initiation of basal insulin therapy between patients who successfully withdrew from insulin therapy and those who had to continue insulin therapy

\begin{tabular}{|c|c|c|}
\hline Patient characteristics & $\begin{array}{l}\text { Patients successfully withdrawing from basal } \\
\text { insulin }\end{array}$ & Patients continuing on basal insulin \\
\hline Male/female $(n)$ & $37 / 24$ & $204 / 111$ \\
\hline Age (years) & $60.1 \pm 13.8$ & $63.7 \pm 12.7^{* *}$ \\
\hline $\begin{array}{l}\text { Duration of diabetes } \\
\text { (years) }\end{array}$ & $4.5 \pm 6.2$ & $11.4 \pm 8.3$ ** \\
\hline \multicolumn{3}{|c|}{ Dose of basal insulin (U/day) } \\
\hline At start of study & $5.2 \pm 1.6$ & $5.7 \pm 1.9$ \\
\hline At 1 month & $6.0 \pm 5.4$ & $8.1 \pm 3.5_{* *}^{*}$ \\
\hline At 3 months & $3.8 \pm 5.8^{\ddagger}$ & $9.7 \pm 5.4_{* *}^{*}$ \\
\hline At 6 months & $0^{\ddagger}$ & $10.9 \pm 6.6 * *$ \\
\hline \multicolumn{3}{|l|}{ HbAlc (\%) } \\
\hline At start of study & $10.86 \pm 2.18$ & $9.95 \pm 1.91^{* * *}$ \\
\hline At 1 month & $9.00 \pm 1.53^{\ddagger}$ & $9.21 \pm 1.53^{\star}$ \\
\hline At 3 months & $7.12 \pm 1.30^{*}$ & $8.23 \pm 1.33 * *$ \\
\hline At 6 months & $6.62 \pm 0.88^{\ddagger}$ & $7.97 \pm 1.34_{* *}^{*}$ \\
\hline \multicolumn{3}{|l|}{$\mathrm{HbAlc}(\mathrm{mmol} / \mathrm{mol})$} \\
\hline At start of study & $95.15 \pm 23.87$ & $85.22 \pm 20.92^{* * *}$ \\
\hline At 1 month & $74.89 \pm 16.68^{*}$ & $77.18 \pm 16.69^{\ddagger}$ \\
\hline At 3 months & $54.34 \pm 14.17^{\ddagger}$ & $66.42 \pm 14.53^{*} *$ \\
\hline At 6 months & $48.85 \pm 9.64^{\ddagger}$ & $63.57 \pm 14.62_{* *}^{*}$ \\
\hline \multicolumn{3}{|l|}{$\operatorname{BMI}\left(\mathrm{kg} / \mathrm{m}^{2}\right)$} \\
\hline At start of study & $27.4 \pm 6.3$ & $24.8 \pm 4.1^{* * *}$ \\
\hline At 1 month & $27.1 \pm 6.0$ & $24.9 \pm 4.0^{* * \dagger}$ \\
\hline At 3 months & $26.6 \pm 6.1$ & $25.0 \pm 4.0^{\ddagger}$ \\
\hline At 6 months & $26.9 \pm 6.3$ & $25.2 \pm 4.0^{\ddagger}$ \\
\hline \multicolumn{3}{|c|}{ Treatment of diabetes with glimepiride, gliclazide, and glibenclamide, $n$ (dosage in $\mathrm{mg}$ ) } \\
\hline At start of study & $3(1) / 0 / 0$ & $\begin{array}{l}86(1.34 \pm 0.84) / 17(29.4 \pm 15.6) / 8 \\
\quad(1.88 \pm 0.67)\end{array}$ \\
\hline At 6 months & $4(0.88 \pm 0.25) / 2(10) / 0$ & $\begin{array}{l}72(0.93 \pm 0.71) / 19(21.1 \pm 12.4) / 4 \\
\quad(0.96 \pm 0.33)\end{array}$ \\
\hline \multicolumn{3}{|c|}{ Treatment of diabetes with rapid-acting insulin/SGLT2I/GLP-1RA/TZD $(n)$} \\
\hline At start of study & $0 / 17 / 0 / 4$ & $0 / 66 / 0 / 27$ \\
\hline At 6 months & $0 / 23 / 4 / 3$ & $24 / 90 / 7 / 26$ \\
\hline
\end{tabular}


Table 2 continued

Patient characteristics Patients successfully withdrawing from basal Patients continuing on basal insulin
insulin

Treatment of diabetes with glinide/BG/ $\alpha-G I / D P P-4 I(n)$
At start of study
$6 / 24 / 7 / 43$
$45 / 96 / 82 / 274$
At 6 months
$6 / 35 / 9 / 44$
$61 / 115 / 92 / 269$

Data are shown as mean \pm SD unless indicated otherwise

$S U$ Sulfonylureas

${ }^{* *}$ Significant at $P<0.05,{ }^{* * *} P<0.01$, and ${ }^{*} P<0.0001$ compared with patients achieving withdrawal from basal insulin after adjustment for age and gender

$\dagger$ Significant at $P<0.001$ compared with data at start of study

\$ Significant at $P<0.0001$ compared with data at start of study

insulin during the observation period, and type of basal insulin. As shown in Table 3, the HRs for duration of diabetes and use of any insulin secretagogues were $0.881 \quad(95 \%$ confidence interval [CI] 0.829-0.935, $P<0.0001)$ and 0.467 (95\% CI $0.280-0.778, P=0.004)$, respectively. In contrast, the HR of BMI was 7.241 (95\% CI 1.761-29.780, $P=0.006)$. Other OAAs and variables, such as HbA1c and basal insulin type, did not affect the withdrawal of basal insulin use in this study.

\section{DISCUSSION}

In this multicenter retrospective observational study, initiation of basal insulin therapy was found to be an effective strategy for the treatment of T2D in a Japanese clinical setting regardless of the basal insulin type selected. In addition, duration of diabetes, BMI, and use of insulin secretagogues were significant determinants for the successful withdrawal of basal insulin therapy, but not selected insulin type. There were no differences in glycemic control among the study participants with T2D on the different basal insulin types-Gla100, Gla300, and Deg. To our knowledge, this is the first study to follow clinical features over a period of 6 months after the initiation of basal insulin and to compare the three types of basal insulin in a clinical setting among Japanese patients with T2D.
The principal objective of this study was to assess the impact of initiating basal insulin therapy among patients with T2D. Following the initiation of basal insulin by the study participants, HbA1c decreased smoothly over time, independently of the type of basal insulin, suggesting that basal insulin therapy may be a powerful strategy for managing T2D in clinical practice. In addition, 61 participants (16.2\%) were able to withdraw from basal insulin therapy within 6 months. The characteristics of that group of participants were short duration of diabetes and high BMI, and the use of medications other than insulin secretagogues by many of the participants. While it is difficult to specify the best protocol for possible withdrawal of insulin treatment, these data indicate several clinical factors for the use of insulin, possibly providing support for the concept of a beneficial effect of " $\beta$-cell rest" with insulin therapy. In this context, insulin therapy would be expected to decrease the secretory demand for endogenous insulin from $\beta$-cells. In contrast, it was difficult for participants using insulin secretagogues, such as SU and glinides, with $\beta$-cell stimulatory effects to withdraw from insulin treatment within 6 months, presumably due to the increased burden on $\beta$-cells. One possible explanation is that these results indicate that the $\beta$-cell function of those patients who were successful in withdrawing from insulin therapy was preserved to a greater degree. In addition, short duration of diabetes was positively associated with the ability of participants to 
Table 3 Adjusted hazard ratios of independent variables for insulin withdrawal within 6 months among patients with type 2 diabetes

\begin{tabular}{|c|c|c|}
\hline Variables & $\begin{array}{l}\text { Adjusted hazard } \\
\text { ratio }(95 \% \mathrm{CI})\end{array}$ & $P$ value \\
\hline Age & $1.017(0.994-1.040)$ & 0.153 \\
\hline Men & $0.767(0.442-1.331)$ & 0.346 \\
\hline Duration of diabetes & $0.881(0.829-0.935)$ & $<0.0001$ \\
\hline Deg (vs. Gla100) & $0.979(0.486-2.185)$ & 0.953 \\
\hline Gla300 (vs. Gla100) & $1.022(0.478-2.185)$ & 0.956 \\
\hline BMI at start of study & $7.241(1.761-29.780)$ & 0.006 \\
\hline HbAlc at start & $0.599(0.123-2.918)$ & 0.526 \\
\hline $\begin{array}{l}\text { Use of SGLT2I at } \\
\text { start }\end{array}$ & $0.736(0.342-1.585)$ & 0.434 \\
\hline Use of BG at start & $1.403(0.916-2.148)$ & 0.119 \\
\hline $\begin{array}{l}\text { Use of insulin } \\
\text { secretagogues at } \\
\text { start }\end{array}$ & $0.467(0.280-0.778)$ & 0.004 \\
\hline $\begin{array}{l}\text { Use of DPP-4I at } \\
\text { start }\end{array}$ & $0.666(0.359-1.233)$ & 0.196 \\
\hline Use of TZD at start & $1.910(0.635-5.749)$ & 0.250 \\
\hline Use of $\alpha$-GI at start & $0.649(0.369-1.143)$ & 0.134 \\
\hline $\begin{array}{l}\text { Addition of GLP- } \\
\text { 1RA during } \\
\text { observation }\end{array}$ & $1.494(0.849-2.630)$ & 0.164 \\
\hline $\begin{array}{l}\text { Addition of rapid- } \\
\text { acting insulin } \\
\text { during observation }\end{array}$ & $0.726(0.450-1.173)$ & 0.191 \\
\hline
\end{tabular}

CI Confidence interval

withdraw from insulin use. It has been reported that at the onset of T2D total pancreatic $\beta$-cell mass is decreased to approximately $50 \%$ of that in healthy persons [12], suggesting that $\beta$-cell function may decline at a constant rate after diabetes onset [13]. The results of these studies suggest that T2D should be treated at an early stage. We also found that a high BMI, which was believed to be accompanied by high insulin secretion due to insulin resistance, was positively associated with successful withdrawal of insulin use. Taking these findings into consideration, the introduction of basal insulin therapy at an early stage of the disease would be beneficial in terms of remission of glucose intolerance with respect to $\beta$-cell insufficiency and preservation of $\beta$-cell function.

In the present study, no difference was found among the three insulin types in terms of changes in HbA1c and BMI at the beginning of the study or after 6 months, including the rate of successful withdrawal of insulin treatment during the observation period. The pharmacokinetic/pharmacodynamic properties of the basal insulin analogues Gla300 and Deg are improved compared with those of Gla100. The EDITION randomized controlled trial (RCT) program, conducted in Japanese persons with T2D, demonstrated that Gla300 provided similar reductions in HbA1c compared with Gla100, but with fewer hypoglycemic episodes [14]. The BRIGHT study, the first RCT to directly compare the efficacy and safety of Gla300 and Deg in insulin-naïve patients with T2D, demonstrated that both analogues provided similar robust improvements in glycemic control with a low risk of hypoglycemia. Benefits were observed with Gla300 in terms of lower hypoglycemia rates during the active titration period (weeks 0-12) when compared with Deg [6]. Indeed, compared with participants using Gla100 and Deg, those using Gla300 seemed to require higher doses of insulin and to experience slowly increased BMI in this study. On the other hand, in two earlier studies, Deg and Gla100 administered once daily in combination with OAAs provided similar long-term glycemic control in insulin-naïve T2D patients with lower rates of nocturnal hypoglycemia when compared with the use of only Deg $[8,15]$. In addition, significantly improved HbA1c, larger reductions in the rates and likelihood of hypoglycemia, and lower risk of treatment discontinuation have been demonstrated with Deg or degludec U200 (the latter which was not available in Japan), compared with Gla300 in insulin-naïve patients with T2D [9]. In that RCT, basal insulins were titrated, targeting the fasting glucose level, apart from the risk of hypoglycemia, in contrast with two studies that used propensity-score 
matching analyses $[9,10]$. The design used in those studies might have made a difference among the basal insulin types. However, in the present study, as well as in previous Japanese prospective, observational studies [16, 17], basal insulins were titrated by attending physicians, targeting hypoglycemia-conscious glucose levels on an individual basis in routine clinical practice. There were fewer reports of hypoglycemic events in these latter two studies $[16,17]$ than in the other Japanese RCT studies $[14,15]$, although the present study did not investigate hypoglycemia. Differences in study design might be a reason why no differences were found in the present study among the three insulin types, including the rate of withdrawal of insulin therapy.

The results of the present study also revealed that bodyweight management was important for successful withdrawal of insulin treatment. The BMI among the $\mathrm{W}$ participants was maintained during the observation period, whereas the BMI among the C participants increased significantly, although the $\mathrm{C}$ participants had significantly lower BMI at the beginning of the study compared to the $\mathrm{W}$ participants. The decreasing $\mathrm{BMI}$ in the $\mathrm{W}$ participants during treatment implied that these participants' improved compliance with diet and exercise therapy reduced the burden on $\beta$-cells. Accordingly, successful withdrawal of insulin treatment might be, as expected, important not only for baseline characteristics but also for ability to ensure lifestyle interventions in a clinical setting to prevent increases in bodyweight.

In this study, the BMI among participants that were started on Deg or Gla100 was significantly increased, whereas the BMI among participants started on Gla300 was not. We believe that any consideration of these results should be careful and conservative. To fully grasp the results, the period of medication use should also be considered. Gla100, Deg, and Gla300 were launched as treatment options in Japan in 2003, 2013, and 2015, respectively, while DPP-4I, GLP-1RA, and SGLT2I were launched in 2009, 2010, and 2014, respectively. Accordingly, it would be difficult to assess the benefits derived from the three types of insulin on a clinical basis because the opportunities for use of the new OAAs or GLP-1RA are inconsistent. In addition, medication changes during the observation period should be also considered, although among the three insulin categories, differences in medication use at the start of the study continued even after 6 months (Table 1). To avoid any such bias, it is necessary to perform further studies involving a larger study population and a shorter recruitment period.

There a several limitations to the study. First, it did not investigate hypoglycemic events accurately because some participants did not self-measure plasma glucose and there were no reported cases of severe hypoglycemia. It is highly likely that the number of hypoglycemic events were underestimated. In addition, it seems that treat-to-target by physician decision was not strictly implemented in the real-world clinical setting, unlike in clinical trials, which also contributed to low incidence of hypoglycemia reported in this study. Taken together, hypoglycemia may have been underreported. Second, the study included the observation of only four data points for a period of 6 months with a limited sample size. In addition, participants were not followed after withdrawal of insulin use. Lastly, habitual and comorbid factors, such as smoking status and activities of daily life, were not assessed either before the study or during the observation period.

\section{CONCLUSIONS}

In this multicenter retrospective observational study, the initiation of basal insulin therapy appeared to represent a powerful strategy for prompt glycemic management, independently of basal insulin type, in a Japanese clinical setting. In addition, the study found that it was possible for participants with short duration of diabetes and sufficient bodyweight control to successfully withdraw from the use of basal insulin. 


\section{ACKNOWLEDGEMENTS}

The authors would like to thank all the participants of this study and all staff members for their assistance in its execution.

Funding. No funding or sponsorship was received for this study or publication of this article. The Rapid Service Fee was funded by the authors.

Authorship. All named authors meet the International Committee of Medical Journal Editors (ICMJE) criteria for authorship for this article, take responsibility for the integrity of the work as a whole, and have given their approval for this version to be published.

Medical writing, editorial, and other assistance. This study is a multicenter collaboration. In addition to the listed authors, the following study investigators were involved in this study (presented in alphabetical order of clinic/hospital). Aoyagi Clinic: Hiroshi Takata; Ayame Medical Clinic: Hideo Ayame; Egusa Genshi Clinic: Genshi Egusa; Ehime University: Shinya Furukawa; Iwamoto Medical Clinic: Masahiro Iwamoto; Hiroshima Kyoritsu Hospital: Hisaaki Morishita; Kagawa Rosai Hospital: Yasuyoshi Iwata; Kurashiki Medical Center: Tadafumi Kaneda; Murakami Memorial Hospital: Mizuho Yamabe; Oshima Clinic: Yasushi Oshima; Tsuchiya General Hospital: Hiroshi Watanabe.

Disclosures. Hideaki Kaneto has received honoraria for lectures and received scholarship grants from Sanofi, Novo Nordisk, Eli Lilly, Boehringer Ingelheim, Taisho Pharma, MSD, Takeda, Ono Pharma, Daiichi Sankyo, Sumitomo Dainippon Pharma, Mitsubishi Tanabe Pharma, Kissei Pharma, Astellas, Novartis, Kowa, Chugai, the Japan Foundation for Applied Enzymology, and A2 Healthcare. Kohei Kaku has been an advisor to, received honoraria for lectures from, and received scholarship grants from Novo Nordisk Pharma, Sanwa Kagaku Kenkyusho, Takeda, Taisho Pharmaceutical Co., MSD, Taisho Toyama Pharma., Astellas, Kissei Pharma., Mitsubishi Tanabe
Pharma. Co., Ono Pharma. Co., Sumitomo Dainippon Pharma, Novartis, Mitsubishi Tanabe Pharma, AstraZeneca, Nippon Boehringer Ingelheim Co., Fujifilm Pharma Co., and Sanofi. Masashi Shimoda and Shuhei Nakanishi have received honoraria for lectures from AstraZeneca and Sanofi, respectively.

Compliance with ethics guidelines. The study was conducted in accordance with the declaration of Helsinki 1964 and its later amendments. Information pertaining to the study was provided to the public on a website (https://h.kawasaki-m.ac.jp/data/dept_010/ ekigaku_s_dtl/) to give the participants the opportunity to opt-out, instead of informed consent being obtained from each individual patient, which in Japan is not a legal requirement at this point in time (under Japanese legislation). In addition, the study and its protocols were approved by the Kawasaki Medical School Hospital's ethics committee (No. 3215-1), the scientific research ethics committee at Murakami Memorial Hospital (201901160), Tsuchiya General Hospital's ethics committee (E181119-4), Kagawa Rosai Hospital's ethics committee (R1-5), Kurashiki Medical Center's ethics committee (910 [481]), and Hiroshima Kyoritsu Hospital's ethics committee (2018-12-21).

Data availability. The datasets generated during and/or analyzed during the current study are not publicly available due to the lack of approval for data sharing from the Kawasaki Medical School hospital's ethics committee.

Open Access. This article is licensed under a Creative Commons Attribution-NonCommercial 4.0 International License, which permits any non-commercial use, sharing, adaptation, distribution and reproduction in any medium or format, as long as you give appropriate credit to the original author(s) and the source, provide a link to the Creative Commons licence, and indicate if changes were made. The images or other third party material in this article are included in the article's Creative Commons licence, unless indicated otherwise in a credit line to the material. If material is not included 
in the article's Creative Commons licence and your intended use is not permitted by statutory regulation or exceeds the permitted use, you will need to obtain permission directly from the copyright holder. To view a copy of this licence, visit http://creativecommons.org/licenses/bync/4.0/.

\section{REFERENCES}

1. Cho NH, Shaw JE, Karuranga S, et al. IDF diabetes atlas: global estimates of diabetes prevalence for 2017 and projections for 2045. Diabetes Res Clin Pract. 2018;138:271-81.

2. Nanditha A, Ma RC, Ramachandran A, et al. Diabetes in Asia and the Pacific: implications for the global epidemic. Diabetes Care. 2016;39:472-85.

3. UK Prospective Diabetes Study (UKPDS) Group. Intensive blood-glucose control with sulphonylureas or insulin compared with conventional treatment and risk of complications in patients with type 2 diabetes (UKPDS 33). Lancet. 1998;352: 837-53.

4. UK Prospective Diabetes Study (UKPDS) Group. Effect of intensive blood-glucose control with metformin on complications in overweight patients with type 2 diabetes (UKPDS 34). Lancet. 1998;352: 854-65.

5. American Diabetes Association. 9. Pharmacological approach to glycemic treatment. Diabetes Care. 2020;43(Suppl 1):S98-110.

6. Rosenstock J, Cheng A, Ritzel R, et al. More similarities than differences testing insulin glargine 300 Units/mL versus insulin degludec 100 Units/mL in insulin-naive type 2 diabetes: the randomized headto-head BRIGHT trial. Diabetes Care. 2018;41: 2147-54.

7. Yamabe $M$, Kuroda $M$, Hirosawa $Y$, Kamino $H$, Ohno H, Yoneda M. Comparison of insulin glargine $300 \mathrm{U} / \mathrm{mL}$ and insulin degludec using flash glucose monitoring: a randomized cross-over study. J Diabetes Investig. 2019;10:352-7.

8. Zinman B, Philis-Tsimikas A, Cariou B, et al. Insulin degludec versus insulin glargine in insulin-naive patients with type 2 diabetes: a 1-year, randomized, treat-to-target trial (BEGIN Once Long). Diabetes Care. 2012;35:2464-71.
9. Tibaldi J, Hadley-Brown M, Liebl A, et al. A comparative effectiveness study of degludec and insulin glargine $300 \mathrm{U} / \mathrm{mL}$ in insulin-naïve patients with type 2 diabetes. Diabetes Obes Metab. 2019;21: 1001-9.

10. Pettus J, Roussel R, Zhou FL, et al. Rates of hypoglycemia predicted in patients with type 2 diabetes on insulin glargine $300 \mathrm{U} / \mathrm{ml}$ versus first-and second-generation basal insulin analogs: The realworld LIGHTNING Study. Diabetes Ther. 2019;10: 617-33.

11. Araki $\mathrm{E}$, Inagaki $\mathrm{N}$, Inoguchi $\mathrm{T}$, et al. Glycemic Target. In: The Japan diabetes society, eds. Treatment Guide for Diabetes. Tokyo, Japan: Bunkodo; 2014;24-26.

12. Finegood DT, Scaglia L, Bonner WS. Dynamics of beta-cell mass in the growing rat pancreas: estimation with a simple mathematical model. Diabetes. 1995;44:249-56.

13. UK Prospective Diabetes Study (UKPDS) Group. UK Prospective Diabetes Study 16 Overview of 6 years' therapy of type 2 diabetes: a progressive disease. Diabetes. 1995;44:1249-58.

14. Terauchi $\mathrm{Y}$, Koyama M, Cheng X, et al. New insulin glargine $300 \mathrm{U} / \mathrm{ml}$ versus glargine $100 \mathrm{U} / \mathrm{ml}$ in Japanese people with type 2 diabetes using basal insulin and oral antihyperglycaemic drugs: glucose control and hypoglycaemia in a randomized controlled trial (EDITION JP 2). Diabetes Obes Metab. 2016;18:366-74.

15. Osonoi T, Onishi $\mathrm{Y}$, Nishida T, Hyllested-Winge J, Iwamoto Y. Insulin degludec versus insulin glargine, both once daily as add-on to existing orally administered antidiabetic drugs in insulin-naïve Japanese patients with uncontrolled type 2 diabetes: subgroup analysis of a pan-Asian, treat-totarget phase 3 trial. Diabetol Int. 2016;7:141-7.

16. Shimoda S, Sato M, Sekigami T, et al. A 1-year, prospective, observational study of Japanese outpatients with type 1 and type 2 diabetes switching from insulin glargine or detemir to insulin degludec in Basal-Bolus Insulin Therapy (Kumamoto Insulin Degludec Observational Study). J Diabetes Investig. 2016;7:703-10.

17. Kobuke K, Yoneda M, Nakanishi S, Ohno H, Maeda S, Egusa G. Efficacy and safety of insulin degludec in Japanese patients with type 1 and type 2 diabetes: 24-week results from the observational study in routine clinical practice. J Diabetes Investig. 2016;7:94-9. 